\title{
An Electronic Program to Predict the Performance of Team Kata Players in terms of Some Sensorimotor Perceptions
}

Dr. Ahmed Samir Yousef Abdelaziz

Introduction and Research Problem:

Sensorimotor Perception is the basis of the knowledge of the outside world through the senses. It is the basis which all other mental processes depend upon. Without it, the individual cannot be aware or remember or imagine or learn or do anything or think about it. In order to know learn something or think about it, we should aware of it. The human responds to certain conditions of sensual stimuli that knock his senses from each side and at every moment. Accordingly, perception is a mental response to certain sensory stimuli to give meaning to what our senses and feelings convey to us (Hussein \& Al-Mufti, 2002; Shebl, 1995; Hijazi, 1996).

The importance of sensory motor perception in the field of sports activity is evident in the successful implementation of complex motor skills as shown in many skills. The sensory motor perception the process of interpreting the information to control the various parts of the body and directing them in the vacuum to the right extent in order to reach the required movement properly, through which the correct and precise direction of the player's hand, arm or any other part of his body participate in the activity of the movement, which helps the player to perform correctly and accurately. (Gomaa, 1993; Shahin, 1998).

The Karate Kata
competition is divided into individual Kata and Team Kata, and the kinetic motif (kata) is a set of pre-set movements, highlighting the importance of the sensorimotor perceptions in the Team Kata through the Team rhythm that is clearly manifested in the performance of all players of the team. As one player in terms of speed and strength appropriate for each movement and direction, and the ability to estimate the distance of the colleague and time and the integration of these factors with each other produces the motor rhythm and integration 
and harmony in performance (Ibrahim \& Abaza, 2005; Sorour, 1994; Abd El-Hamid, 2010).

Mohamed Mohamed ElHady (1995), Tamer Saber Mohamed (2015) noted that employing the scientific advances in applying the laws and scientific theories related to the human movement, using artificial intelligence technology in order to benefit from the results of sensory motor perception, contributes to benefiting from the beginning from selecting the junior and directing him to the type of the sports activity which suits his its various biomechanical capabilities, as well as predicting the impact of training operations on the growth and development of the preparations and capabilities of the player in an effective manner that enables the player to achieve continuous progress in his sports activity, which is the essence of the training process . (El-Hady, 1995; Mohammed, 2015).

According to the researchers, the importance of the research is clear that the selection of suitable person for the exercise of sports activity in general and Team Kata in particular is the first steps to success in this area, which provides a greater opportunity to reach the desired goal, and agree with what Ahmed Ibrahim (2005), Abd El-Qader Abd El-Baki (1992), Essam Abdel-Khaleq (2003) mentioned as the selection of juniors on the basis of scientific objective sound contributes to the development of sports performance, and reduces the possibility of false choice, which is a waste of time and effort and potential, so there must be a set of tests and standards scientifically codified and suitable for the age stage of juniors, which are considered the main factors that must be guided by the process of selection of juniors in karate sport (Ibrahim, 2005; Abd El-Baqi, 1992; El-Khaleq, 2003).

Through the experience of the two researchers in the field of training and arbitration of karate, and the study of the international law of karate, the researchers found that one of the most important criteria that assess the performance of Team Kata according is the "uniformity of motor 
performance". That is, rhythmic movement synchronized between the players, and the synchronization between players depends on the sensorimotor perceptions as the players of the one team of the Team Kata (three players) are asked to perform the kata as one player in terms of (Appropriate force for each movement- distance perception-time perceptionperformance stabilityexpression of the meaning of each movement). The researchers believe in the importance of selection in the field of sports as this represents the nucleus and the basis in the upbringing of the generations of sports, and based on the fact that the correct selection today is the nucleus of national teams in the future. So the researchers see that through the proper selection based on the scientific bases of the sensorimotor perceptions, we can predict the performance of Team Kata players in the Team karate.

\section{Research objective:}

The research aims to predict the performance level of Team Kata players in terms of some sensory motor perceptions by identifying:

- Sensory motor perceptions of Team Kata players in karate.

- Predictive equations were developed to predict the level of skill performance of Team Kata players in terms of sensory motor perceptions under study which have high correlation with the degree of performance.

- Designing an electronic program to predict the level of skill performance of the Team Kata players in terms of predictive equations of sensory motor perceptions under research.

\section{Research Questions:}

1. What are the sensory motor perceptions of Team Kata players in karate?

2. Is it possible to predict the level of skill performance of Team Kata players in terms of the sensory motor perceptions under study which have high correlation with the degree of performance?

3. Can an electronic program be designed to predict the level of skill performance of the Team Kata players in terms of predictive equations of sensory motor perceptions?

\section{Research procedures:}

The two researchers used the descriptive approach because of its suitability to the nature of the study and its procedures. 
Research population and sample:

Research population:

The research population represents the Team Kata teams of Dakahlia team, Mansoura University team, Nasiriyah sports club and AlNasr sports club for the $2016 / 2017$ sports season and it consists of (27) players in all various age groups.

Research sample:

The sample of the research was chosen using the purposive sample from the Team Kata players of the 2016/2017 sports season. The total number of players was 18 , representing 6 teams represented by Dakahlia team, Mansoura University young team, Nasiriyah sports club, $(66.6 \%)$ of the total research population, the players, sample

\section{Table (1)}

Mean, standard deviation, median and coefficient of skewness of the research sample In the primary variables under research $=18$

\begin{tabular}{l|l|l|l|c|c|c|c}
\hline \hline Team & $\begin{array}{l}\text { Player } \\
\text { number }\end{array}$ & Variable & $\begin{array}{l}\text { Unit of } \\
\text { measurement }\end{array}$ & Mean & $\begin{array}{l}\text { Standard } \\
\text { deviation }\end{array}$ & Median & Skewness \\
\hline \hline \multicolumn{7}{l}{ Dakahlia team "Men" } \\
\hline \multirow{3}{*}{ First } & 1 & Age & Year & 22.33 & 0.58 & 22 & 1.74 \\
\cline { 2 - 8 } & 2 & Weight & Kg & 70.33 & 1.53 & 70 & 0.94 \\
\cline { 2 - 8 } & 3 & Height & $\mathrm{M}$ & 168.00 & 2.65 & 169 & -1.46 \\
\hline \multirow{3}{*}{ Second } & 1 & Age & Year & 20 & 1 & 20 & 0 \\
\cline { 2 - 8 } & 2 & Weight & Kg & 75.53 & 4.16 & 74 & 1 \\
\cline { 2 - 8 } & 3 & Height & M & 172.67 & 2.52 & 173 & -1 \\
\hline
\end{tabular}

Mansoura University Team "Young" above 18 years

\begin{tabular}{c|c|c|c|c|c|c|c}
\hline \multirow{3}{*}{} & 1 & Age & Year & 19 & 1 & 19 & 0 \\
\cline { 2 - 7 } & 2 & Weight & $\mathrm{Kg}$ & 77.33 & 2.52 & 77 & 1 \\
\cline { 2 - 8 } & 3 & Height & $\mathrm{M}$ & 175 & 2.00 & 175 & 0 \\
\hline \hline
\end{tabular}

Assiut Journal For Sport Science Arts of the research, obtained the first three ranks of their respective age groups.

Research volume:

The total sample of the research was (54) players divided into (18) players who are respondents of the primary research sample, and (36) players are the respondents of the pilot sample, the two researchers benefited from the total sample in order to conduct the scientific procedures for the tests used in the research.

Homogeneity of the research sample:

The two researchers conducted the homogeneity between the members of the research sample before applying the tests to the variables in the research as shown in Table (1):

Assiut Journal For Sport Science Arts


Follow Table (1)

Mean, standard deviation, median and coefficient of skewness of

the research sample In the primary variables under research $=18$

\begin{tabular}{c|c|c|c|c|c|c|c}
\hline \hline Team & $\begin{array}{c}\text { Player } \\
\text { number }\end{array}$ & Variable & $\begin{array}{c}\text { Unit of } \\
\text { measurement }\end{array}$ & Mean & $\begin{array}{c}\text { Standard } \\
\text { deviation }\end{array}$ & Median & Skewness \\
\hline \hline
\end{tabular}

Nasiriyah sports club "Juniors" 15 years

\begin{tabular}{|l|c|c|c|c|c|c}
1 & Age & Year & 14.67 & 0.58 & 15 & -1.73 \\
\hline 2 & Weight & $\mathrm{Kg}$ & 54 & 9.00 & 54 & 0 \\
\hline 3 & Height & $\mathrm{M}$ & 166 & 2.08 & 167 & -1.29 \\
\hline
\end{tabular}

Al-Nasr sports club "Juniors" 12 years

\begin{tabular}{|l|c|c|c|c|c|c|}
\hline 1 & Age & Year & 11.67 & 0.58 & 12 & -1.73 \\
\hline 2 & Weight & Kg & 44.67 & 6.51 & 45 & -0.23 \\
\hline 3 & Height & M & 150 & 3.46 & 152 & -1.73 \\
\hline
\end{tabular}

Al-Nasr sports club "Juniors" 11 years

\begin{tabular}{c|c|c|c|c|c|c|c}
\hline & 1 & Age & Year & 10.67 & 0.58 & 11 & -1.73 \\
\hline & 2 & Weight & Kg & 37.33 & 4.16 & 36 & 1.29 \\
\hline & 3 & Height & $\mathrm{M}$ & 143 & 3.61 & 142 & 1.15 \\
\hline & 1 & Age & Year & 10.67 & 0.58 & 11 & -1.73 \\
\hline \hline
\end{tabular}

It is clear from Table (1) that the values of skewness coefficients ranged between (1.73 and 1.29) as they were limited between $(\mathbf{+ 3}, \quad \mathbf{- 3})$ indicating the homogeneity of the respondents of the research sample in the variables under research.

\section{Tools and methods of data} collection:

The two researchers used many tools to collect data and information related to the subject of research in order to achieve the objectives of the research and achieve the following:

\section{Reference Survey:}

The two researchers conducted a baseline survey of the references and researches that can be seen in the field of different sensory motor perceptions in the field of sports in general and in the karate sport (Team Kata) in particular in order to be able to collect the biggest volume of sensory motor perceptions to be used in the application of research and among the perceptions that have been used: Distance perceptionvisual sense compared to the distance-Sense of time required to move (Motor compared to the time)-sensory motor perception of performance speed- time sense-direction sense-distance perceptionperception of the force required 
to jump- space perceptionvacuum sense)

\section{Data collection forms:}

- Expert survey forms to determine sensory motor perceptions and the relative importance of testing these perceptions of the Team Kata players under research. Annex no.(2).

- Forms to record the measurements of anthropometric variables and the sensory motor perceptions chosen. Annex no.(4)

Tests used: Annex (3) Test (Moving forward with the normal step - 50\% sense of the distance of the challenge Perception of the jump distance in front with the two legs together -Perception of lateral foot distance-Direction perception test-Visual sense compared to distance- Vacuum sense- Sensory motor measurement compared to time (2 movements, including 3 seconds) - Sensory motor perceptions compared to time (2 movements, including 2 seconds).

Methods of assessment of the technical performance: The Kata Unso of the Team Kata players were filmed under the search using the video camera and the video was presented to five members of the Egyptian Karate Federation. Annex no.(1) to evaluate the technical performance of the Team Kata under research, the performance score has been estimated by the standard assessment according to the conditions established by international law to assess the Team Kata.

\section{Equipment and devices used} in conducting the tests: Karate mat-Medical weight scale (kg)-Alrstamitr device to measure the body's height (cm)-Electronic stopwatch (Casio)-Wide cloth tape for blocking vision-Ruler with two sliding indicators for measuring visual sense-(1) Video camera for filming the performance of Team Kata players-Number (1) TripodAdhesive tape and control signs -Measurement tape for distance determination $(\mathrm{cm})$.

\section{Pilot studies:-}

- Expert Survey: (Annex 2)

From Saturday $8 / 4 / 2017$ to Thursday, 20/4/2017, an expert questionnaire survey was prepared for determining the sensory motor perceptions and the relative importance of the tests of these skills to the Team 
Kata players under research. Expert selection conditions (Annex. 1).

\section{- Second exploratory study:}

It was conducted in the period from Tuesday 9/5/2017 until Sunday $14 / 5 / 2017$ in order to ascertain the validity of the tests used and their suitability for the sample respondents through:

- Ensuring the extent to which the tests that the researchers designed to measure the results of the trials and their suitability for the various stages of the age of the "sample respondents" under the research, before conducting scientific parameters of these tests.

- Determining the time required for the measurement and testing process.

- Ensuring the validity of the tools and devices used, and identifying the most important difficulties that may exist during the application of tests.

\section{- Third pilot study:}

It was conducted in the period from Tuesday 16/5/2017 Sunday $28 / 05 / 2017$ in order to determine the scientific coefficients of those tests (Validity-Reliability) on a sample of 54 players that included the basic study players and players from outside the sample of the research. The two researchers used the discrimination validity to calculate the validity of the tests and the method of test application and then reapplication of the test (TEST \& RE TEST) to calculate the reliability.

Scientific parameters for research tests:

- Validity of the sensory motor perceptions tests under research

\section{(Discrimination validity)}

The researchers used the discrimination validity method to calculate the validity of the tests under research. The tests were applied in the period from Tuesday 16/05/2017 Sunday $28 / 50 / 2017$ to a different group in the skill level of karate players for different age groups of 54 players, including the basic study players "distinctive", and a second group of non-distinctive karate players, and then the researchers made a peripheral comparison between the upper quartile and the lowest quartile "27\%" to identify the validity of the tests under study to identify the differences between the results of the two groups as shown in Table (2) 
Table (2)

Discrimination validity of the tests of sensory motor perceptions of the Team Kata players under research

\begin{tabular}{l|l|c|c|c|c|c}
\hline \hline S & Tests & \multicolumn{2}{|c|}{ Upper quartile } & \multicolumn{2}{|c|}{ Lower quartile } & T value \\
\cline { 2 - 6 } & Mean & Deviation & Mean & Deviation & \\
\hline \hline 1 & $\begin{array}{l}\text { Step distance } \\
\text { perception } \\
\text { (Moving forward } \\
\text { with normal step) }\end{array}$ & 1.4 & 0.8 & 9.5 & 2.3 & 12.4 \\
\hline 2 & $\begin{array}{l}\text { Challenge } \\
\text { distance } \\
\text { perception } \\
\begin{array}{l}\text { (Sense of 50\% of } \\
\text { the challenge } \\
\text { distance) }\end{array}\end{array}$ & 1.6 & 1.1 & 14.4 & 4.2 & 11.0 \\
\hline 3 & $\begin{array}{l}\text { Jump distance } \\
\text { perception in } \\
\text { front with the two } \\
\text { legs together }\end{array}$ & 3.3 & 1.6 & 12.1 & 3.5 & 8.7 \\
\hline 4 & $\begin{array}{l}\text { Lateral leg } \\
\text { distance } \\
\text { perception }\end{array}$ & 0.2 & 0.4 & 5.2 & 0.9 & 18.6 \\
\hline 5 & $\begin{array}{l}\text { Direction } \\
\text { perception test }\end{array}$ & 1.7 & 0.4 & 5.8 & 0.5 & 23.2 \\
\hline 6 & $\begin{array}{l}\text { Visual sense } \\
\text { compared to } \\
\text { distance }\end{array}$ & 0.0 & 0.0 & 0.0 & 0.0 & 0.0 \\
\hline 7 & $\begin{array}{l}\text { Vacuum sense } \\
\text { (Covering a } \\
\text { distance of 3m) }\end{array}$ & 7.5 & 1.7 & 12.2 & 1.2 & 8.4 \\
\hline 8 & Time sense & 3.9 & 2.9 & 25.3 & 5.2 & 13.4 \\
\hline 9 & $\begin{array}{l}\text { Motor sense } \\
\text { compared to time } \\
\text { "3s" }\end{array}$ & 1.7 & 0.2 & 2.9 & 0.2 & 13.6 \\
\hline 10 & $\begin{array}{l}\text { Motor sense } \\
\text { compared to time } \\
\text { "2s" }\end{array}$ & 1.8 & 0.1 & 2.9 & 0.2 & 20.7 \\
\hline \hline & Tabulated Tat 0.05 & & & & \\
\hline
\end{tabular}

Tabulated $\mathrm{T}$ at $0.05=2.262$ 
Table (2) shows that there are statistically significant differences between each of the score of the extinctive upper quartile sample and the non-extinctive lowest upper quartile. The computed values are greater than their tabulated value at a significant level of 0.05 . This means the ability of these tests to discriminate between the levels, i.e. they are considered valid test for measuring the characteristics for which they were developed. This isn't applied on the test no. (6) the visual sense compared to distance.

Second: Validity coefficient of the tests under study (TestRetest):

The researchers found the reliability of the selected tests under Test-Retest in the period from Tuesday 16/05/2017 to Monday 22/05/2017 and with an interval of 7 days between the two applications. Table (3) shows:

Table (3)

Correlation coefficients between the first and second tests in the physical variables under research (to calculate reliability) n1 $=$ n $2=9$

\begin{tabular}{l|l|c|c|c|c|c|c}
\hline \hline S & Tests & \multirow{2}{*}{$\begin{array}{c}\text { Error } \\
\text { amount }\end{array}$} & \multicolumn{2}{|c|}{ Upper quartile } & \multicolumn{2}{|c|}{ Lower quartile } & T \\
\cline { 4 - 6 } & & Mean & Deviation & Mean & Deviation & value \\
\hline \hline 1 & $\begin{array}{l}\text { Step } \\
\text { distance } \\
\text { perception } \\
\text { (Moving } \\
\text { forward with } \\
\text { normal step) }\end{array}$ & $\mathrm{cm}$ & 3.00 & 2.08 & 3.13 & 2.34 & 0.721 \\
\hline 2 & $\begin{array}{l}\text { Challenge } \\
\text { distance } \\
\text { perception } \\
\text { Sense of }\end{array}$ & $\mathrm{cm}$ & -3.53 & 3.65 & -3.33 & 3.37 & 0.701 \\
\hline $\begin{array}{l}\text { 50\% of the } \\
\text { challenge } \\
\text { distance) }\end{array}$ & $\begin{array}{l}\text { Jump } \\
\text { distance } \\
\text { perception in } \\
\text { front with } \\
\text { the two legs } \\
\text { together }\end{array}$ & $\mathrm{cm}$ & 3.67 & 1.32 & 3.11 & 1.69 & 0.856 \\
\hline 4 & $\begin{array}{l}\text { Lateral leg } \\
\text { distance } \\
\text { perception }\end{array}$ & $\mathrm{cm}$ & 1.97 & 1.89 & 0.89 & 2.62 & 0.848 \\
\hline 5 & $\begin{array}{l}\text { Direction } \\
\text { perception } \\
\text { test }\end{array}$ & $\mathrm{m}$ & 3.27 & 1.8 & 3.39 & 1.24 & 0.892 \\
\hline \hline
\end{tabular}


Follow Table (3)

Correlation coefficients between the first and second tests in the

physical variables under research (to calculate reliability) n1 $=$ n $2=9$

\begin{tabular}{|c|c|c|c|c|c|c|c|}
\hline \multirow[t]{2}{*}{$\mathbf{S}$} & \multirow[t]{2}{*}{ Tests } & \multirow{2}{*}{$\begin{array}{c}\text { Error } \\
\text { amount }\end{array}$} & \multicolumn{2}{|c|}{ Upper quartile } & \multicolumn{2}{|c|}{ Lower quartile } & \multirow{2}{*}{$\begin{array}{c}\mathbf{T} \\
\text { value }\end{array}$} \\
\hline & & & Mean & Deviation & Mean & Deviation & \\
\hline 6 & $\begin{array}{l}\text { Visual } \\
\text { sense } \\
\text { compared } \\
\text { to distance }\end{array}$ & $\mathrm{cm}$ & 0.0 & 0.0 & 0.0 & 0.0 & 0.0 \\
\hline 7 & $\begin{array}{l}\text { Vacuum } \\
\text { sense } \\
\text { (Covering } \\
\text { a distance } \\
\text { of } 3 \mathrm{~m} \text { ) } \\
\end{array}$ & $\mathrm{cm}$ & 9.73 & 1.06 & 10.18 & 1.82 & 0.724 \\
\hline 8 & Time sense & sec. & 14.11 & 10.95 & 10.89 & 7.56 & -0.731 \\
\hline 9 & $\begin{array}{l}\text { Motor } \\
\text { sense } \\
\text { compared } \\
\text { to time } \\
\text { "3s" }\end{array}$ & sec. & 2.83 & 0.66 & 2.73 & 0.38 & -0.777 \\
\hline 10 & $\begin{array}{l}\text { Motor } \\
\text { sense } \\
\text { compared } \\
\text { to time } \\
\text { "2s" }\end{array}$ & sec. & $\begin{array}{c}1.95 \\
1.8\end{array}$ & $\begin{array}{c}0.29 \\
0.1\end{array}$ & $\begin{array}{l}1.99 \\
2.9\end{array}$ & $\begin{array}{c}0.31 \\
0.2\end{array}$ & $\begin{array}{c}-0.909 \\
20.7\end{array}$ \\
\hline
\end{tabular}

Tabulated $\mathrm{R}$ value at significance level of $0.05=0.643$

It is clear from Table (3)

that there is a statistically significant correlation between the first application and the second application in the sensory motor perception tests from the first to the seventh test under research with the exclusion of the sixth test. The correlation coefficients ranged between (0.701 and 0.892) where the calculated "R" values are greater than their tabulated values at significance level of 0.05 . This refers to the reliability of the test scores when reapplying it under the same conditions. It was also found that there is a statistically significant negative correlation between the first application and the second application in the sensory motor perception tests from the eighth to the tenth test under research. The correlation coefficients values ranged between $(-0.731,-0.909)$ where the calculated "R" values are greater than their tabulated 
values at significance level of 0.05. This refers to the reliability of the test scores when reapplying it under the same conditions.

\section{Executive procedures of the research:-}

In order for the two researchers to achieve the objective of the research they carried out a series of procedures, including:

- The two researchers used the descriptive approach to suit the nature of the study and its procedures.

- Determining the sample of the research using the purposive sample of the Team Kata players of the sports season 2016/2017, where the sample consists of (18) Kata players representing 6 teams (66.6\%) of the total research population as well as conducting the homogeneity of the research sample.

- The researchers used many tools to collect data and information related to the subject of research in order to achieve the objectives of the research and achieve its objectives (survey-data collection forms- tests that measure sensory motor perception-motor) Annex (3)
- Evaluation of the performance of the players during the arbitration of the performance of the players of the "basic study sample of the research" of the Team Kata (UNSO) in order to determine the degree of skill performance in the Team Katas.

- The two researchers carried out the pilot studies in the period from 08/04/2017 to $28 / 05 / 2017$, which differed in their objectives between the experts' survey (Annex 2), assuring the validity of the tests used and their suitability for the sample respondents, determining the time required for the measurement process and tests and conducting scientific tests of the research tests (Discrimination validityReliability coefficient) for the tests of the sensory motor perceptions under research.

- To establish the relationship between the results of the players in the tests of sensory motor perceptions through the application of linear regression analysis using a StipWise method to predict the skill level of the Team Kata players (dependent variable) by informing the results of the players in the tests of sensory 
motor perception with high correlation

(independent variable) .

- Predictive equations were developed to predict the level of skill performance of Kata players in terms of sensory motor perception under study of high correlation with the degree of performance.

- Designing an electronic program to predict the level of skill performance of the Team Kata players in terms of predictive equations of sensory motor perception. Annex (6).

Statistical Treatments:

The two researchers used the non-parametric statistical method to suit the nature of the research.

The researchers conducted the statistical treatments through the program Microsoft Excel 2010 SPSS $16 \& 7.5$, and were as follows:

- Mean-standard deviationmedian-skewness coefficient of the homogeneity of the research teams.

- "T" test to find the discrimination validity of the tests of kinetic perceptions by finding differences using the peripheral comparison (upper quartile - lower quartile).
- Use the Pearson (t) correlation coefficient to find the reliability coefficient for the standardized tests.

- Using Multiple Linear Regression Analysis in Step wise method to analyze predictive equations to predict the level of skill performance of Team Kata players in terms of sensory motor perceptions under study.

\section{Results Presentation and} Discussion:

- Presentation of multiple linear regression analysis to predict the performance of the group in terms of sensory motor perceptions under research.

The two researchers, through the multiple linear regression results using StepWise of the sensory motor perceptions of the Team Kata Players, concluded two models for predicting the efficiency of Team Kata performance in terms of sensory motor perceptions, as follows:

1. Model 1: Predicting the level of the performance of the Team Kata in terms of test (9) motor sense compared to time "3s". Table (5)

2. Model 2: Predicting the level of Team Kata 
performance in terms of (9) motor sense compared to time
$3 \mathrm{~s}$ ", and test (4) recognizing lateral foot distance. Table (6)

\section{Table (5)}

regression analysis to predict the performance of the group in terms of sensory motor perceptions under research (Model 1)

\begin{tabular}{|c|c|c|c|c|c|c|c|c|c|c|}
\hline & \multirow[t]{2}{*}{ Model } & \multicolumn{2}{|c|}{ Constant } & \multirow{2}{*}{$\begin{array}{c}\text { Covariance } \\
\text { Beta }\end{array}$} & \multirow{2}{*}{ t } & \multirow{2}{*}{ Sig. } & \multirow{2}{*}{$\begin{array}{c}\text { Partial } \\
\text { correlation }\end{array}$} & \multirow{2}{*}{$\begin{array}{c}F \\
\text { value }\end{array}$} & \multirow[t]{2}{*}{ Sig. } & \multirow{2}{*}{$\begin{array}{c}\mathbf{R} \\
\text { Predictability }\end{array}$} \\
\hline & & B & $\begin{array}{l}\text { Standard } \\
\text { deviation }\end{array}$ & & & & & & & \\
\hline \multirow[t]{3}{*}{1} & $\begin{array}{c}\text { Regression } \\
\text { constant }\end{array}$ & 6.19 & 0.431 & & 14.363 & 0.001 & & \multirow{3}{*}{18.47} & \multirow{3}{*}{0.001} & \multirow{3}{*}{0.262} \\
\hline & \multicolumn{7}{|c|}{ Motor sense compared to time " $3 \mathrm{~s}$ " } & & & \\
\hline & Test 9 & 0.786 & 0.183 & 0.512 & 4.298 & 0.001 & 0.512 & & & \\
\hline
\end{tabular}

Kata level $=6.194+(.7860 \times$ Test $91 \mathrm{~s} 3)$

Table (5) "Model 1" shows the predictability of the effectiveness of Team Kata performance in terms of the sensory motor perceptions under research as follows:

The first model shows a statistically significant effect of motor sense compared to time "3s" test (9) on the Team Kata performance where $\mathrm{T}$ value is statistically significant at 0.05 , and it is possible to predict the Team Kata performance level in terms of motor sense compared to time "3s" test (9),

\section{Table (6)}

Regression analysis of the predictability of the performance of the Team Kata in terms of sensory motor perceptions under research (Model 2)

\begin{tabular}{|c|c|c|c|c|c|c|c|c|c|c|}
\hline & \multirow[t]{2}{*}{ Model } & \multicolumn{2}{|c|}{ Constant } & \multirow{2}{*}{$\begin{array}{c}\text { Covariance } \\
\text { Beta }\end{array}$} & \multirow{2}{*}{$\mathbf{t}$} & \multirow{2}{*}{ Sig. } & \multirow{2}{*}{$\begin{array}{c}\text { Partial } \\
\text { correlation }\end{array}$} & \multirow{2}{*}{$\begin{array}{c}\mathrm{F} \\
\text { value }\end{array}$} & \multirow[t]{2}{*}{ Sig. } & \multirow{2}{*}{$\begin{array}{c}\text { R } \\
\text { Predictability }\end{array}$} \\
\hline & & B & $\begin{array}{l}\text { Standard } \\
\text { deviation }\end{array}$ & & & & & & & \\
\hline \multirow[t]{5}{*}{2} & $\begin{array}{c}\text { Regression } \\
\text { constant }\end{array}$ & 6.461 & 0.436 & & 14.826 & 0.001 & & \multirow{5}{*}{12.125} & \multirow{5}{*}{0.001} & \multirow{5}{*}{0.322} \\
\hline & \multicolumn{7}{|c|}{ Motor sense compared to time "3s" } & & & \\
\hline & Test 9 & 0.786 & 0.183 & 0.512 & 4.298 & 0.001 & 0.512 & & & \\
\hline & \multicolumn{7}{|c|}{ Lateral foot distance perception } & & & \\
\hline & Test 4 & -0.095 & 0.045 & -0.245 & -2.127 & 0.038 & -0.245 & & & \\
\hline
\end{tabular}

Kata level $=6,461+(.7770 \times$ Test $913 \mathrm{~s})+(-0.095 \times$ Test 4$)$

Assiut Journal For Sport Science Arts 
Table (6) "Model 2" shows the predictability of the effectiveness of Team Kata performance in terms of the sensory motor perceptions under research as follows:

The second model shows that there is a statistically significant effect of test 9 and test 4 on the level of Team Kata performance, where $\mathrm{T}$ value is statistically significant at 0.05 , and the level of Team Kata performance can be predicted in terms of test (9) motor sense compared to time "3s" and test (4) lateral foot distance perception, the predictability of the regression equation 0.322, and the covariance between the independent variable of test (9) of the motor sense compared to time " $3 \mathrm{~s}$ " and the dependent variable of the Team Kata performance is 0.506 and the covariance between the independent test, test (4) of the lateral foot distance perception and the dependant variable of the Team Kata performance level is 0.245 .

The results suggest that the equation of the second model can be used to predict the first Team Kata in terms of test (9) of motor sense compared to time "3s" and test (4) of lateral foot distance perception and it is (Kata level $=6.461+$ $(0.7770 \times$ Motor sense compared to time test "3s" + ($0.095 \times$ Lateral foot distance)

- Presentation of the electronic program to predict the performance level, Annex (6).

\section{Program idea:}

The program idea is based on the practical application of the forecast equation (multiple linear regression) to maximize its benefit by designing an electronic program that helps to calculate the forecast equation through the user by entering the effective tests and contributing to a large percentage in the degree of skill performance of the Kata, the program calculates the predictive degree of the performance level.

\section{Equations within the program:}

The equations within the program consist of two parts, the first one is related to the programming codes for the program design, and the second part is for the forecast equation 
derived from the statistical treatments of the study and it is: Kata level $=6.461+$ $(0.7770 \times$ motor sense compared to time " $3 \mathrm{~s} "$ test $)+(-$ $0.095 \times$ lateral foot distance perception test)

The equation within the program is as follows:

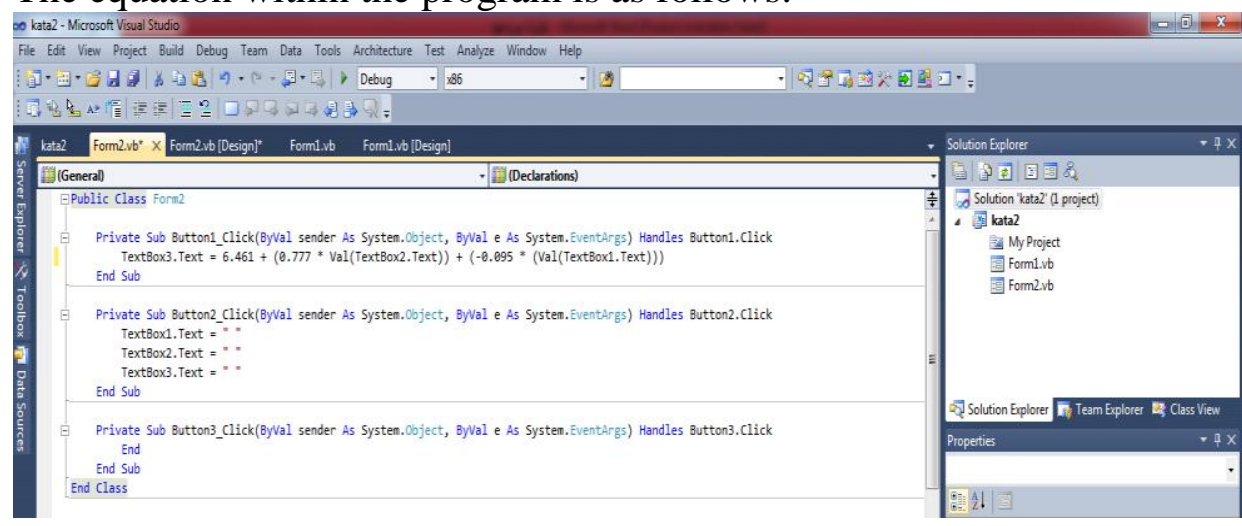

Figure (2) Forecast equation components used in the electronic program to predict the degree of skill performance level of Team Kata players

\section{Second: Discussion of the Results:}

The results of the study in Table (4), (5), (6) of the multiple linear analysis using StepWise method for the sensory motor tests of the Team Kata players under study showed the use of two predictive tests to predict the skill performance of the Team Kata players and they are test no.(9) motor sense compared to time "3s" and test no.(4) lateral foot distance perception. The researcher attributed the importance of the two tests in giving a clear indication of the players' possession of the skills and sensory motor perceptions required by the Team Kata players as the fourth test (lateral foot distance perception) gives a clear indication of the player's efficiency in executing the transitional movements during the performance of different technical techniques within the Kata, and his possession of the skills of the ability to determine the strength and distance required to perform Kata skills during the team performance to synchronize the movements of the players to form one unit during the performance and achieve the 
most important criteria of Team Kata assessments which is the "Uniformity" (17). The test no. (9) of the motor sense compared to time " $3 \mathrm{~s}$ " refers to the player's cognitive ability of the time sense compared to movement. This is one of the most important sensory abilities that should be available in the players of the Team Kata with various time rhythms and they shall be shown by the Team Kata players in a Team rhythm as if they are one player in terms of speed and strength appropriate for each movement and the ability to estimate the competitor's ability, distance, time and the integration of these factors with each other produces the movement, integration and harmony in performance, and the greater harmony in performance increased the degree granted to this performance, and vice versa. The less the harmony is, the less is the degree given to this performance. This is in line with what Khatab (2006), Mulle (2001) and Frank et al. (2003) have found. The sensorimotor perceptions help estimate the motor quickness of the body's lamps accurately through the coupling of the sensory motor information and the central orders in order to participate in the development of motor rhythm and this is known as the time division of the movement and the mutual dynamic work between intensity and relax or work and stoppage, this is consistent with how the player performs for the ninth test (Khattab, 2006; Jeannerod et al., 2003; Muller, 2001)

\section{Conclusions:}

In the light of the objectives and questions of the research and based on the research findings, the researcher concluded the following findings:

- The most important sensory motor perceptions associated with Team Kata players in karate were (distance perception- sense of time required to move (motor compared to time).

- Establishing two equations through the Multiple Linear Regression results using StepWise Method of sensory motor perceptions of the Team Kata Players to predict that there are two models for predicting the efficiency of Team Kata performance in 
terms of sensory motor perceptions, as follows:

$\checkmark$ Equation of the first model to predict the level of first Team Kata performance in terms of test (9) motor sense compared to time "3s" and it is:

(Kata level $=6.194+$

$(.7860 \times$ Motor sense compared to time (3 s)

$\checkmark \quad$ Equation of the second model to predict the level of first Team Kata performance in terms of test (9) of the motor sense compared to time " $3 \mathrm{~s} "$ and test (4) of the lateral foot distance perception in terms of the test (9) the movement sensor compared to the time of the "3" and the test (4)

$($ Kata level $=6.461+(0.7770 \times$ Motor sense compared to time "3s" test $)+(-0.095 \times$ lateral foot distance perception)

- The possibility of designing an electronic program to predict the level of skill performance of the Team Kata players in terms of the predictive equations of sensory motor perceptions under research

\section{Recommendations:}

- It is necessary to be guided by the sensory motor perceptions of the Team Kata players in the content of the educational and training programs of the karate juniors.

- Using the results of the players in test (9) of the motor sense compared to time "3s" and test (4) of the lateral foot distance perception to predict the level of skill performance of Team Kata players in karate. - Using the electronic program in directing Individual Kata players towards Team performance in the Kata.

- The application of training programs to develop the sensory motor development compared to time and the distance recognition of the Team Kata players in karate.

\section{References:}

\section{1- Ahmed Mahmoud Ibrahim} (2005): Encyclopedia of the determinants of theoretical and applied sports training for the planning of training programs for karate sport, Munsha'at AlMa'aref, Alexandria.

\section{2- Ahmed Mahmoud} Ibrahim, Atef Mohamed Abaza (2005): The scientific and applied foundations for the planning of training programs for the motor movement (Kata) in karate sport, Munsha'at AlMa'aref, Alexandria.

\section{3- Asa'ad Sorour (1994):} Learn Karate and defend 
yourself, Dar Maktabat AlHilal, Beirut.

\section{4- Tamer Saber Mohammed}

(2015): Building an expert system on the basis of biomechanics to evaluate the motor performance of the triple jump competition, unpublished PhD thesis, Faculty of Physical Education,

Mansoura University.

5- Hussein Hijazi Abd ElHamid (2010): An Analytical study of the motor rhythms of the players of the high level in the Team Kata of karate sport, unpublished master thesis, Faculty of Physical Education, Mansoura University.

6- Hamdy Eweis Gomaa (1993): Building a test battery for sensory motor perception of children aged 6-9 years, $\mathrm{PhD}$ thesis, Faculty of Physical Education for Boys, Helwan University.

\section{7- Rehab Mustafa Shahin} (1998): A proposed program for the development of neuromuscular compatibility and its impact on sensory motor perception and the level of skill performance in Ballet, Master Thesis, Faculty of Physical Education for Girls in Cairo, Helwan University.
8- Abd El-Qader Refa'at Abd El-Baqi (1992): Building a set of tests for the selection of football juniors (10-12) year in light of some determinants related to excellence in the game, Master Thesis, Faculty of Physical Education for Boys, University of Alexandria.

9- Essam Abd El-Khaleq (2003): Sports Training, Dar Al Ma'arif, 11th Edition.

\section{0- Attiyat Mohamed}

Khattab (2006): Fundamentals of Exercise and Rhythmic Exercises, Al-Kitab Publishing Center, Cairo.

11- Fatima Nasser Hussein, Perivan Abdullah Al-Mufti (2002): A Comparative Study of the development of Cognitive Capacities (SensoryMotor) Using Hayod and Dayton Scales for Kindergarten Children (4-5 Years), Journal of Physical Education, Volume 11, Issue 3.

\section{2- Fayza Mohamed Shebl} (1995): The impact of proposed exercises for the development of some sensory motor perception on the accuracy of the skill of transmission in the volleyball for female beginners, Master 
Thesis, Faculty of Physical Education, Tanta University.

13- Mohamed Mohamed ElHady (1995): Using Information Systems and Account Technology in the Development of Egyptian Education ", Towards a Better Future for Information Technology in Egypt, Research and Studies of the First Scientific Conference of Information Systems and Computer Technology, Egyptian Society for Information Systems and Computer Technology, Cairo.

\section{4- Mostafa Mohammed} Hijazi (1996): Sensory motor perception and level of achievement in some jump competitions, Master Thesis, Faculty of Physical Education for Boys, Zagazig University.

15- Farrer,Frank,Paillard, Jeannerod (2003) : The Role of Proprioception in Action Recognition Elsvier, junuray.

\section{6- Stefan Muller} :PsychophWillkurlicherBewe gungen (2001) : inaasthesie der Geschwindigkeit EineneuartigeMethodezurerstm aligenrhebbung von Unterschiedsschwellen in den KinasthetischenWahrnehmung en der Armbewegungen, Diss., Mathematisch-HeinUniversities, Dusseldorf.

1. www.wkf.net 